\title{
Impact compression and tensile testing by means of a Charpy pendulum
}

\author{
V. Mentl ${ }^{1} \&$ J. Dzugan ${ }^{2}$ \\ ${ }^{I}$ Skoda Research Ltd., Czech Republic \\ ${ }^{2}$ COMTES FHT, Czech Republic
}

\begin{abstract}
Mathematical modelling and virtual testing of components and structures represent a useful and economical tool for design and safety assessment. The so called basic mechanical properties which can be found in material standards are not relevant in cases where the real service conditions differ from those applied during testing. Thus e.g. mechanical behaviour at higher strain rates can be interesting for the car components when the simulation of crash situations is used during structure development. The dynamic compression tests are usually performed by means of drop towers, dynamic tensile tests by means of high speed hydraulic testing machines or the Hopkinson bar method. At the Mechanical Testing Laboratory of the SKODA Research Inst. in Pilsen, Czech Republic, an instrumentation of a Charpy pendulum testing machine was realised in order for it to be possible to perform dynamic compression and tensile tests. A new striking tup and load measurement system were designed and calibrated. At the same time, new software was developed which makes it possible to evaluate the test force-deformation record. The correctness of the instrumentation and software was verified by comparison of measured and evaluated values of energies and deformations. A very good agreement was obtained. An international round-robin within the framework of the ESIS TC5-Subcommittee on "Mechanical testing at intermediate strain rates" is realised at present.
\end{abstract}

\section{Impact tensile testing}

For the purposes of instrumented tensile testing, the Charpy pendulum was modified so that the force during the test could be measured. For this purpose a special load cell element was designed on the basis of tensometric measurement, 
see Fig.1, [1]. This solution made it possible to use the load measuring element repeatedly. The other structural modification shown in Fig.2 should ensure the correct position of the striker with respect to specimen position. The load cell calibration was performed statically at an MTS test machine.

The correctness of the instrumentation was checked by means of comparison of tensile tests at static and impact loading for a common structural steel. The static tests were performed at ZWICK testing machine. Both static and impact tensile tests were carried out at room temperature.

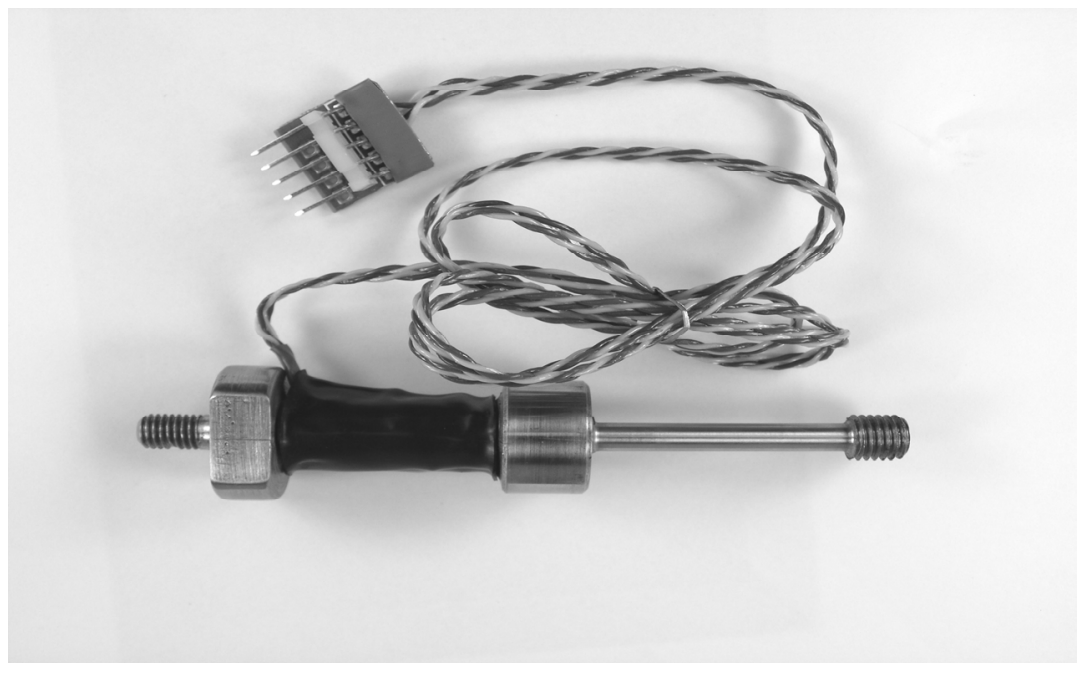

Figure 1: $\quad$ Load measuring element and test bar.

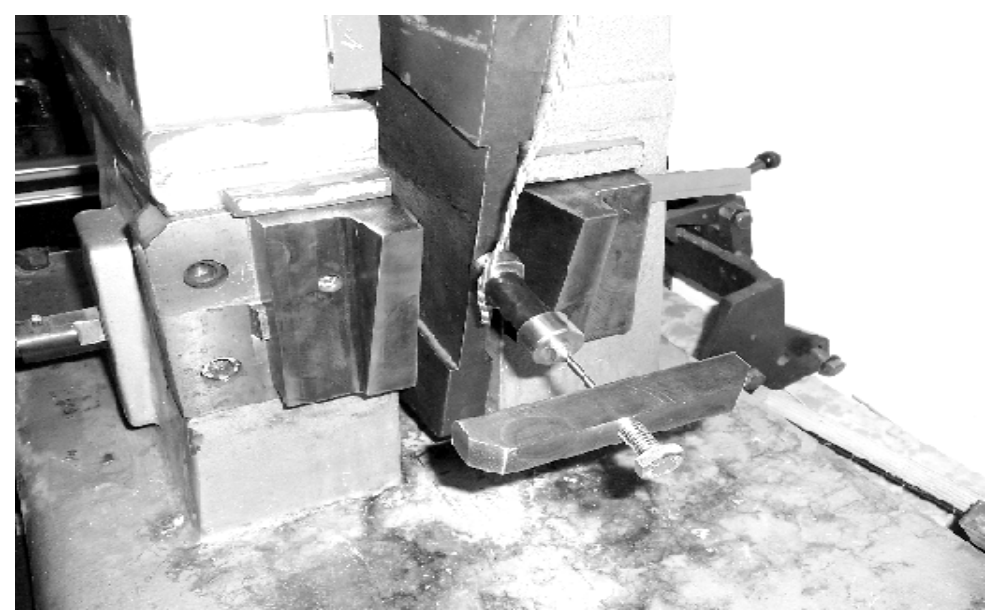

Figure 2: $\quad$ Load cell, test specimen and pendulum modification. 


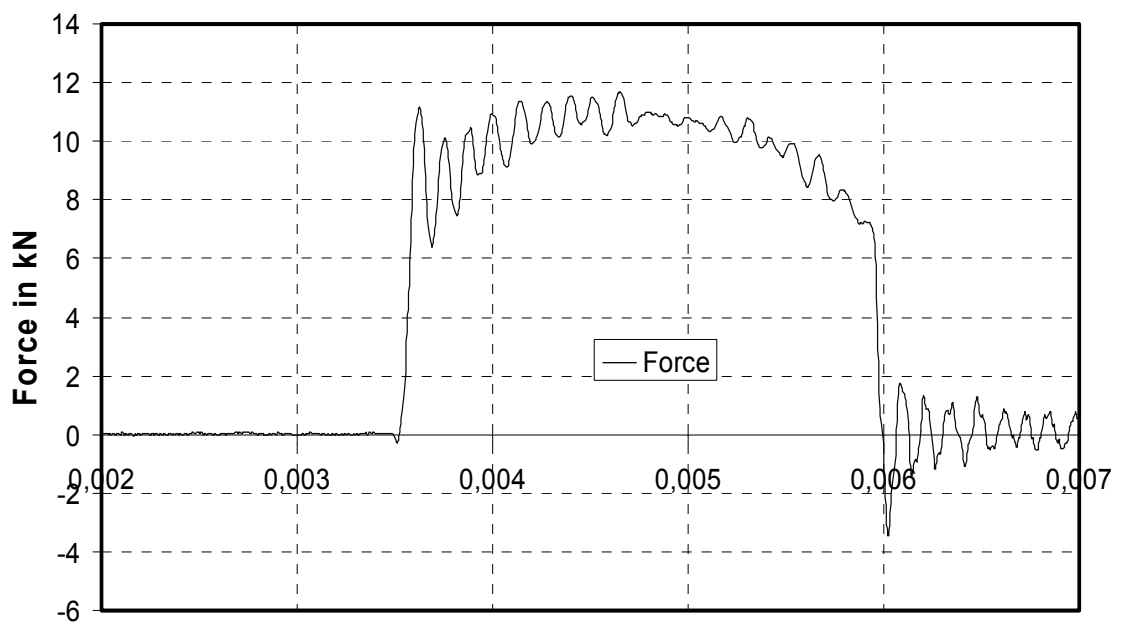

Time in $\mathbf{s}$

Figure 3: $\quad$ Example of an impact tensile test record.

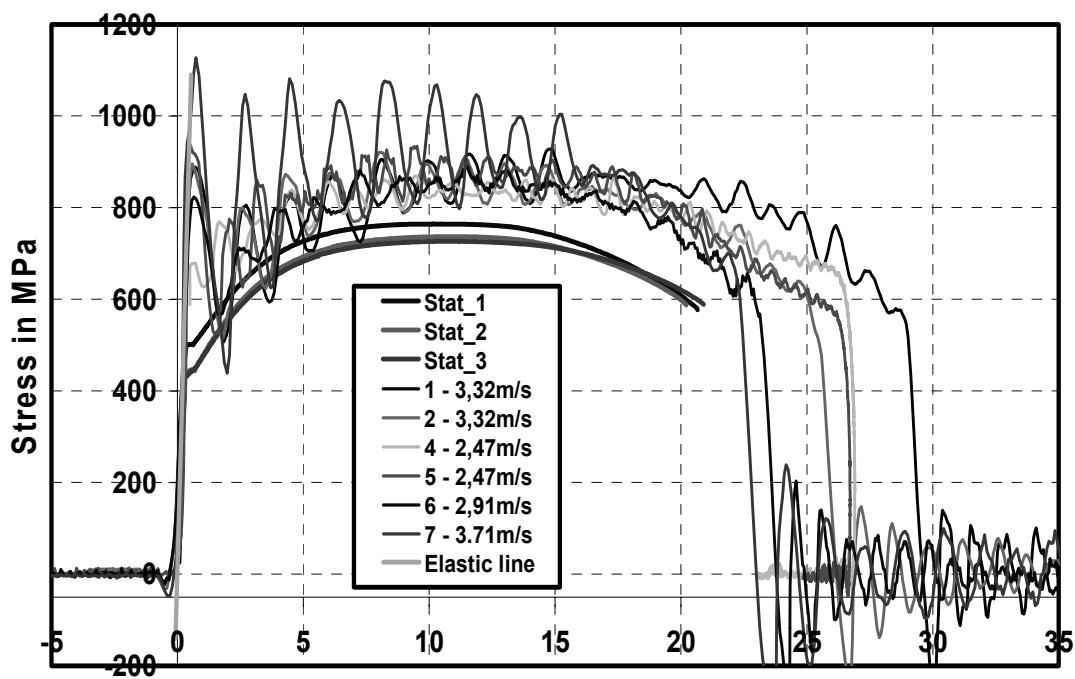

Strain in \%

Figure 4: Comparison of static and dynamic tensile test results.

\section{Impact compression testing}

The compression testing is performed at uniaxial testing of test specimens usual of cylindrical shape whose overall dimensions and shape take into consideration the mechanical properties of the material in question, the capabilities of the test device and the way how the friction is eliminated or minimized. 
The compression tests at intermediate strain rates $(1-10 \mathrm{~m} / \mathrm{s})$ are usually performed at elektro hydraulic testing machines or drop weight towers that ensure the uniaxial loading. Nevertheless, the purchase of such rest machines often means additional costs for the respective laboratory, what in the case of rarely realized tests of this kind can cause ineffective economy.

This article describes the alteration of traditional Charpy pendulum that is thus able to perform the compression tests at rates up to $5 \mathrm{~m} / \mathrm{s}$.

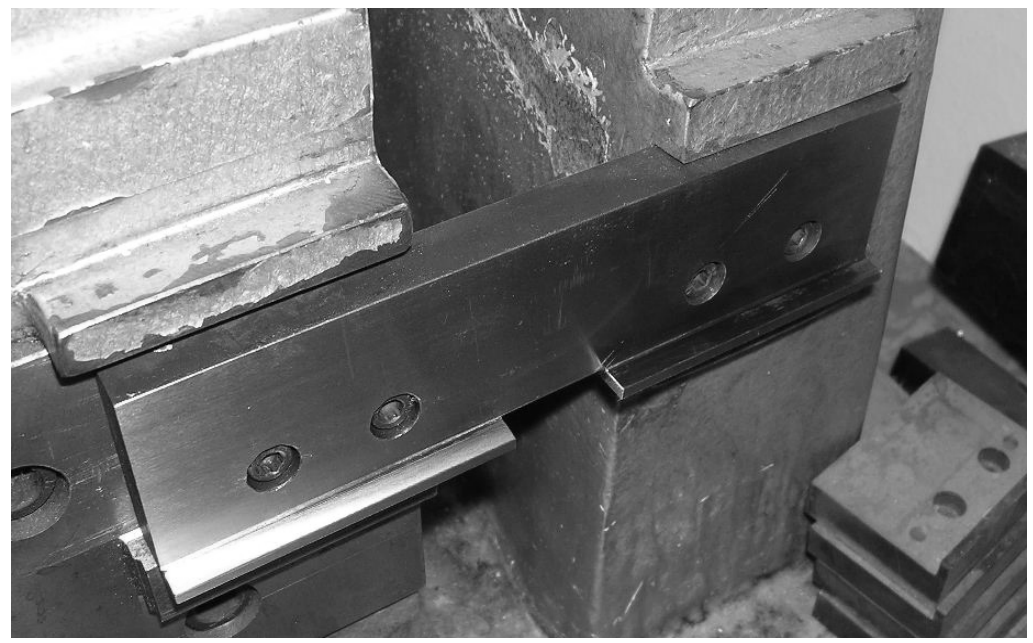

Figure 5: New support for the test bars.

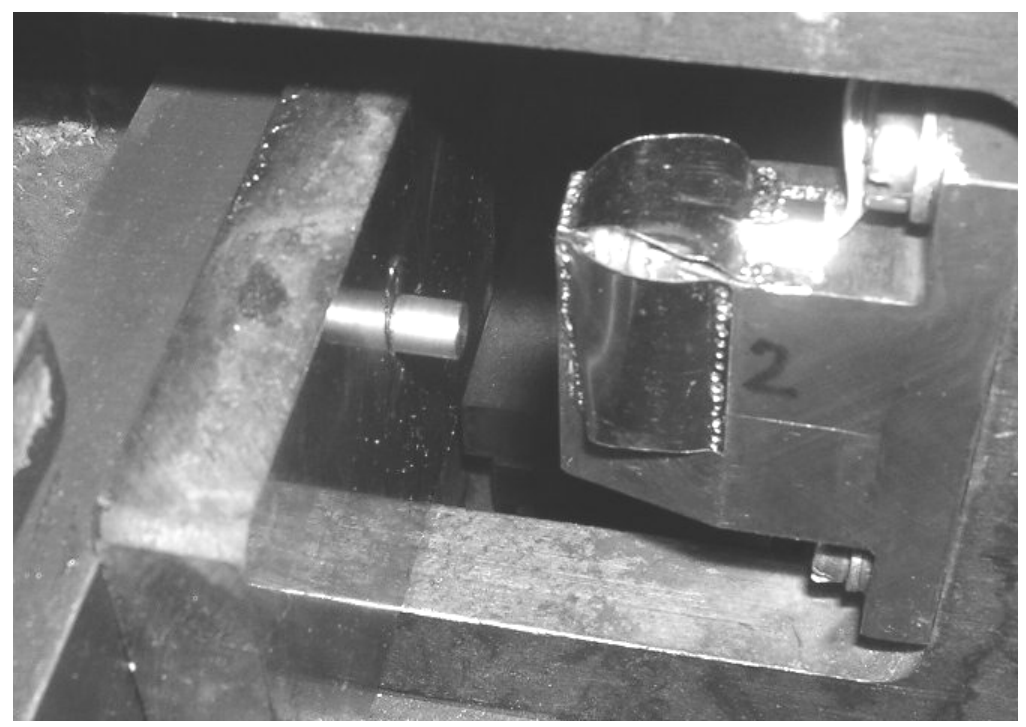

Figure 6: New instrumented flat tup, a distance plate and a test bar set up. 


\section{Charpy design alterations}

A traditional Charpy pendulum, (used for the instrumented Charpy V-noch tests and/or dynamic fracture toughness testing) was re-designed for the purposes of impact compression testing. For the alterations see Figs. 5-8. Static tensile test results of two alternatives of Al-Alloy are shown at Fig. 9.

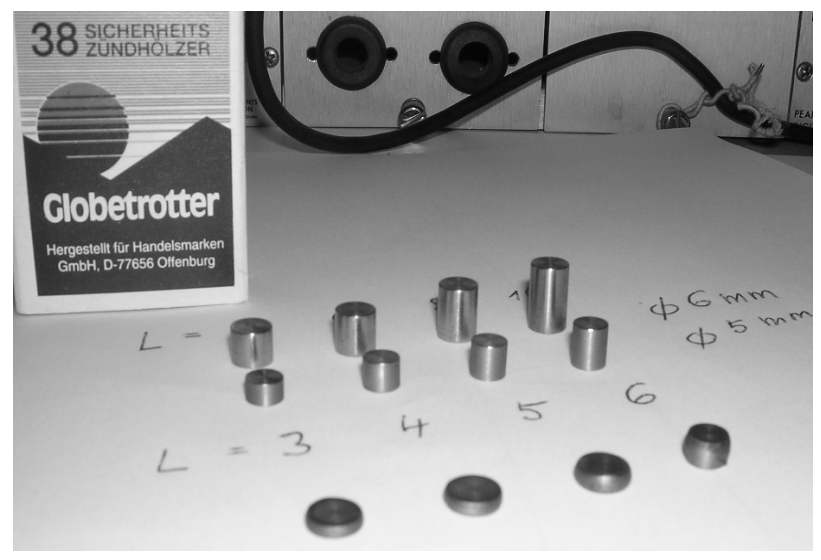

Figure 7: Test specimens before and after testing.

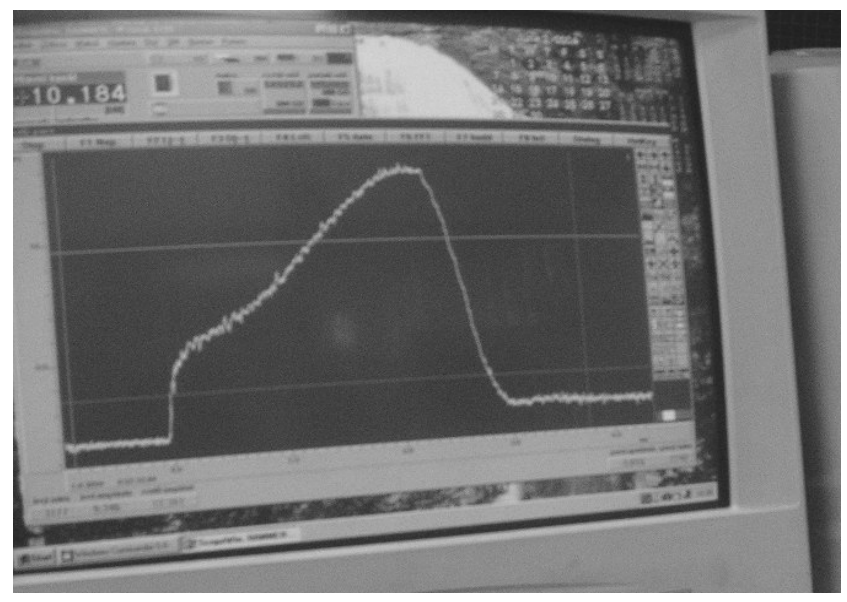

Figure 8: An example of test record.

\section{Conclusion}

The performed Charpy pendulum modification made it possible to carry out impact tensile and compression tests by means of Charpy pendulum testing machine. 


\section{Tensile test results for $\mathrm{Al} 1$ and $\mathrm{Al} 2$ Results:}

\begin{tabular}{c|c|c|c|r|r|r|r|r|c}
$\mathrm{Nr}$ & Designation & $\begin{array}{c}\text { Diameter d0 } \\
\mathrm{mm}\end{array}$ & $\begin{array}{c}\mathrm{SO} \\
\mathrm{mm}^{2}\end{array}$ & $\begin{array}{c}\mathrm{E} \\
\mathrm{GPa}\end{array}$ & $\begin{array}{c}\mathrm{Rp} 0,2 \\
\mathrm{MPa}\end{array}$ & $\begin{array}{c}\mathrm{Rm} \\
\mathrm{MPa}\end{array}$ & $\begin{array}{c}\mathrm{Ag} \\
\%\end{array}$ & $\begin{array}{c}\mathrm{A} \\
\%\end{array}$ & $\begin{array}{c}\mathrm{RB} \\
\%\end{array}$ \\
\hline 1 & $1 \_1$ & 6,00 & 28,27 & 62,7 & 129,61 & 139,26 & 1,38 & 11,06 & 68,6 \\
\hline 3 & $1-2$ & 6,00 & 28,27 & 62,4 & 129,96 & 138,83 & 1,54 & 12,84 & 69,0 \\
\hline 4 & $1 \_3$ & 5,95 & 27,81 & 57,6 & 130,50 & 139,02 & 1,48 & 11,29 & 68,3 \\
\hline 5 & $2-1$ & 6,02 & 28,46 & 20,6 & 34,12 & 76,46 & 30,38 & 52,86 & 85,4 \\
\hline 6 & $2 \_2$ & 6,02 & 28,46 & 19,7 & 31,13 & 77,23 & 32,51 & 57,01 & 84,8 \\
\hline 7 & $2 \_3$ & 5,99 & 28,18 & 29,2 & 33,09 & 76,73 & 29,62 & 47,98 & 85,1
\end{tabular}

\section{Series graph:}

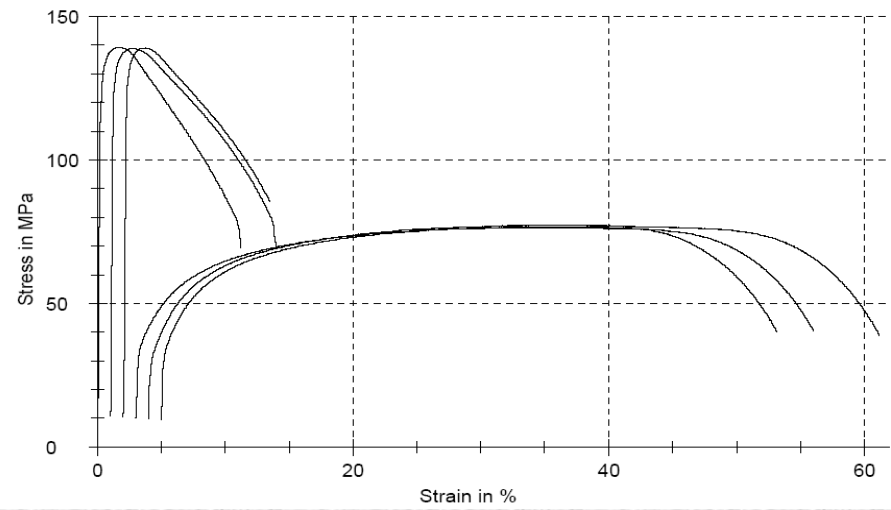

\section{SKODA Vyzkum s.r.o. Plzen}

Figure 9: $\quad$ Static tensile test results.

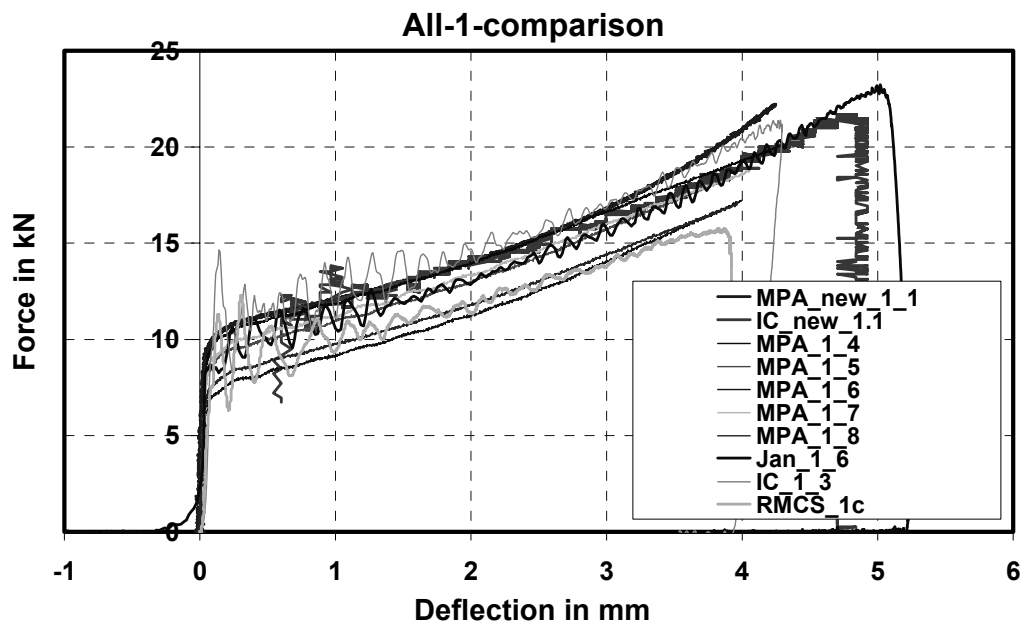

Figure 10: Round-robin comparison of Al-1-alloy compression test records of several labs, [2]. 


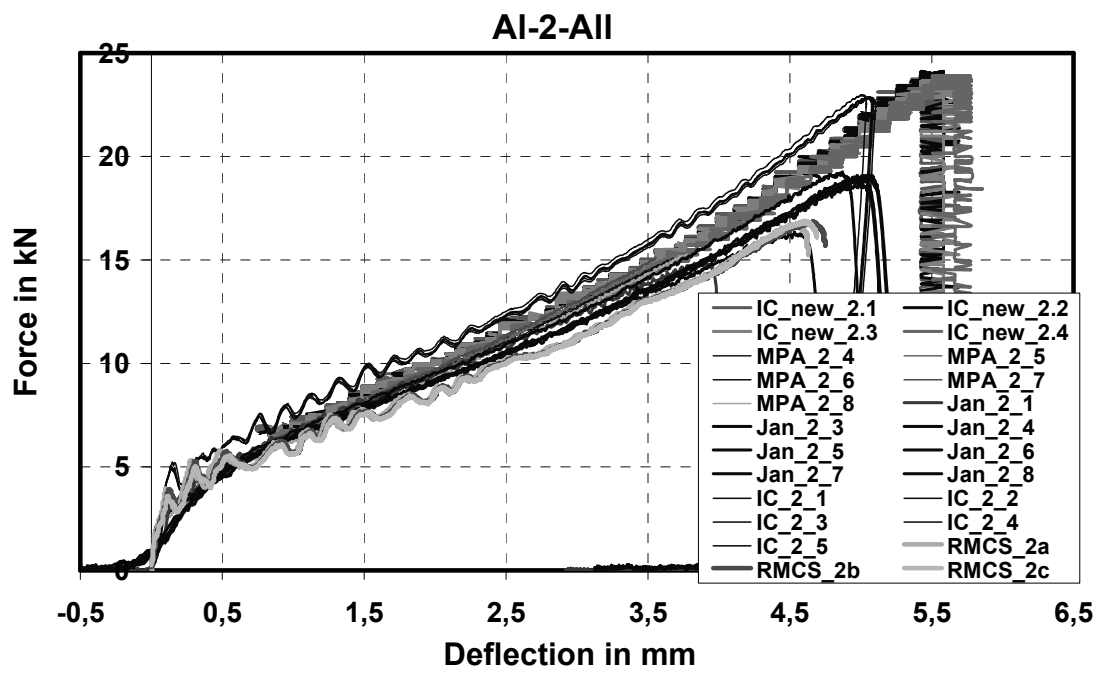

Figure 11: Round-robin comparison of Al-2-alloy compression test records, [2].

\section{References}

[1] Brozik M.: Instrumentation of Charpy pendulum for the purposes of dynamic tensile testing (Instrumentace kyvadlového rázového kladiva při zkoušce rázem v tahu,in Czech), BSc. Thesis, University of West Bohemia, Plzen, 2007.

[2] Dzugan J., Mentl V.: Compression Round Robin Test Results, ESIS TC5 Meeting, CORUS UK, 2007. 